\title{
Torg Ratio In Normal Ageing Population: No Risk of
}

\section{Stenosis}

\author{
Necat Koyun ${ }^{1^{*}}$, Mehmet Ata Gökalp ${ }^{2}$ \\ ${ }^{1}$ Van Yuzuncu Yul University, Faculty of Medicine, Department of Anatomy, Van, Turkey \\ ${ }^{2} V$ an Yuzuncu Yol University, Faculty of Medicine, Department of Trauma and Orthopedic Surgery, Van, Turkey
}

\begin{abstract}
Canal/body or Torg's ratio has been agreed as a reliable method to detect cervical spinal stenosis. Age changes of cervical canal diameter and the ratio have been seldom analyzed in the cohort of normal adults. Our objective is to undertake the age changes in decades from healthy young to the elderly subjects.

Sagittal diameter (SD) of the spinal canal and anteroposterior diameter of the vertebral body (VB) were taken on the lateral cervical radiographs consisting of normal appearance from 104 males and 102 females.

SD showed significant gender differences and insignificant age changes. VB changed with age significantly in both sex, and showed sex difference. Torg ratio was found above 0.9 and changed with age. The ratio also indicated no difference between sexes.

The male/female difference declared previously might not be a consistent finding. The present study suggested that bone cervical canal might diminish in normal ageing persons without existence of the cervical stenosis and/or risk of myelopathy. Our findings might be peculiar to our subject group, which need to be confirmed by the further studies.
\end{abstract}

Keywords: Age change, canal/body ratio, cervical canal stenosis, sex difference

\section{Introduction}

Cervical spinal stenosis or narrowing often encountered in the lower segment has been found to be related to neurologic injury $(1,2)$. It was also confirmed as a causative factor in the neuropraxy of the cervical spinal cord in sport traumas (2). To determine the dimension of the cervical spinal canal in normal subject, a number of studies on roentgenological measurements of the anteroposterior (AP) diameter of the cervical canal have been carried out (3, 4, 5). Computed tomography measurements of the AP diameter, width, and cross-sectional area of the bony cervical canal have also been derived from normal adults (5, 6). Sagittal diameter/ vertebral body ratio or Torg's ratio was addressed as an indicator of the degree of cervical spinal narrowing (7). Since this ratio excludes magnification error resulting from nonstandardized film-tube distances, it has been considered as a reliable method in the measurement of the spinal stenosis and may be measured on plain films $(5,8)$. The ratio of less than 0.80 has a high sensitivity for reversible cervical cord neuropraxia $(\mathrm{CCN})$ and the risk of lasting neurological injury $(8,9)$. There has been few studies concerning cervical spinal canal changes with age. Tanaka (10) showed some correlation with age for the AP diameters of the vertebral body and the spinal canal. Lee et al. (11) reported the changes in the mid-sagittal diameters according to age in Korean. Ishikawa et al. (12) studied the age-related changes cervical spinal cord and the cervical spinal canal. There has been disagreement on the changes of cervical spinal canal with age. Because it is most reliable measurement for the spinal disorder, the present study attempted to elucidate the age and gender changes of Torg's ratio of the cervical spine in a normal, aging population from Turkish individuals.

\section{Material and methods}

Ethical committee approval from institutional ethical board was obtained. The materials used in the course of this work consist of plain lateral radiographs of X- Ray device (E7869X; Toshiba, Tokyo, Japan) of cervical vertebral columns (C1-7) of 206 subjects (104 males and 102 females), all of whom were volunteers (university students and medical/paramedical staff). The radiographs showing pathologic findings such as spondylosis, tumors or cystic lesions and the subjects with a 
Koyun and Gökalp/ Cervical Torg Ratio In Healthy Individuals

Table 1. Descriptive Analysis of Our Subjects By Age and Sex

\begin{tabular}{lcc}
\hline Decades & Male $(\mathrm{n})$ & Female $(\mathrm{n})$ \\
\hline $11-20$ & 20 & 24 \\
$21-30$ & 40 & 31 \\
$31-40$ & 19 & 13 \\
$41-50$ & 10 & 15 \\
$51-70$ & 15 & 19 \\
Total & 104 & 102 \\
\hline
\end{tabular}

Table 2. Distribution of sagittal diameter of cervical canal according to age groups and sex (Values are in millimetres)

\begin{tabular}{cccccccccccc}
\hline & Decades & \multicolumn{2}{c}{1} & \multicolumn{2}{c}{2} & \multicolumn{3}{c}{3} & 4 & 5 \\
\hline & & Mean & StD & Mean & StD & Mean & StD & Mean & StD & Mean & StD \\
\hline \multirow{2}{*}{ C2 } & Male & $22.48 \mathrm{~A}$ & 1.66 & $21.80 \mathrm{~A}$ & 3.33 & $22.53 \mathrm{~A}$ & 2.32 & $21.81 \mathrm{~A}$ & 2.56 & $21.65 \mathrm{~A}$ & 2.92 \\
& Female & $19.78 \mathrm{~B}$ & 2.56 & $19.67 \mathrm{~B}$ & 4.66 & $21.12 \mathrm{~B}$ & 2.27 & $20.03 \mathrm{~B}$ & 2.27 & $19.44 \mathrm{~B}$ & 2.57 \\
$\mathrm{C} 3$ & Male & $19.07 \mathrm{~A}$ & 1.52 & $18.85 \mathrm{~A}$ & 2.64 & $19.21 \mathrm{~A}$ & 1.44 & $18.52 \mathrm{~A}$ & 2.08 & $17.91 \mathrm{~A}$ & 2.15 \\
& Female & $17.56 \mathrm{~B}$ & 1.62 & $17.59 \mathrm{~B}$ & 1.32 & $17.78 \mathrm{~B}$ & 1.28 & $17.86 \mathrm{~B}$ & 1.74 & $17.20 \mathrm{~B}$ & 1.92 \\
& Male & $18.45 \mathrm{~A}$ & 1.79 & $18.07 \mathrm{~A}$ & 1.97 & $18.59 \mathrm{~A}$ & 1.89 & $18.09 \mathrm{~A}$ & 2.02 & $17.31 \mathrm{~A}$ & 2.04 \\
$\mathrm{C} 4$ & Female & $17.17 \mathrm{~B}$ & 1.67 & $16.98 \mathrm{~B}$ & 1.39 & $17.04 \mathrm{~B}$ & 1.61 & $17.52 \mathrm{~B}$ & 1.45 & $17.06 \mathrm{~B}$ & 2.22 \\
& Male & $18.62 \mathrm{~A}$ & 1.69 & $18.14 \mathrm{~A}$ & 2.22 & $18.80 \mathrm{~A}$ & 1.75 & $18.03 \mathrm{~A}$ & 1.72 & $17.54 \mathrm{~A}$ & 2.04 \\
$\mathrm{C} 5$ & Female & $16.74 \mathrm{~B}$ & 2.48 & $16.81 \mathrm{~B}$ & 1.66 & $17.03 \mathrm{~B}$ & 1.41 & $17.55 \mathrm{~B}$ & 2.29 & $16.95 \mathrm{~B}$ & 2.39 \\
& Male & $18.42 \mathrm{~A}$ & 1.72 & $18.06 \mathrm{~A}$ & 2.45 & $18.89 \mathrm{~A}$ & 1.55 & $17.86 \mathrm{~A}$ & 1.78 & $17.50 \mathrm{~A}$ & 3.29 \\
$\mathrm{C} 6$ & Female & $16.97 \mathrm{~B}$ & 1.33 & $17.11 \mathrm{~B}$ & 1.49 & $17.34 \mathrm{~B}$ & 1.82 & $15.87 \mathrm{~B}$ & 4.88 & $16.75 \mathrm{~B}$ & 2.41 \\
& Male & $18.66 \mathrm{~A}$ & 1.51 & $17.70 \mathrm{~A}$ & 2.58 & $18.89 \mathrm{~A}$ & 1.43 & $17.63 \mathrm{~A}$ & 1.58 & $17.68 \mathrm{~A}$ & 1.91 \\
$\mathrm{C} 7$ & Female & $16.57 \mathrm{~B}$ & 3.82 & $17.43 \mathrm{~B}$ & 1.67 & $17.16 \mathrm{~B}$ & 1.42 & $17.89 \mathrm{~B}$ & 1.58 & $16.74 \mathrm{~B}$ & 2.30 \\
\hline
\end{tabular}

The difference between the gender averages receiving different capital letters is significant. $(\mathrm{p}<0.05) \mathrm{A}, \mathrm{B} \downarrow \quad \mathrm{C}$ : Cervical vertebral columns

history of trauma, systemic disease such as rheumatoid arthritis, surgery in the spine or neck pain were excluded. The subjects were grouped into five decades (Table 1). Radiographs were taken with a standardised technique (volunteers in supine position with cervical vertebra columns plain lateral a film-focus distance of $110 \mathrm{~cm}$ ) that had good technical quality and normal appearance according to radiologist's report.

The lateral roentgenogram of the cervical spine was obtained with the neck in the neutral position and the subject in standing. The film-tube distance was fixed constant at $100 \mathrm{~cm}$. The central $\mathrm{x}$-ray beam usually passes through the fourth cervical vertebra. Radiographs were placed on a viewing box. To derive Torg ratio, the distances for sagittal diameter of the spinal canal (SD) and anteroposterior diameter of the vertebral body (VB) were determined by marking the related points with a pencil and a hand lens (Figure 1). The measurements used in the present study were described elsewhere (8). Briefly; SD was defined as the distance from the midpoint of the posterior surface of the vertebral body to the nearest point on the corresponding fusion line of the lamina-the spinous process. VB was defined as the distance between the midpoints of the anterior and the posterior vertebral surfaces. The required distances between points were measured by using Vernier caliper calibrated to $0.01 \mathrm{~mm}$ (Figure 2). Torg ratio was calculated by the formula of $\mathrm{SD} / \mathrm{VB}$.

\section{Results}

Magnification error in all lateral radiographs was negligible due to the standardized technique used. Torg ratio also was ratified to be unaffected by magnification in our study. Since the present study originally aimed at giving and debating the results concerning canal/body ratio, the changes of sagittal diameter and vertebral body were referred in short as the following.

In our study, the SD showed significant gender differences and insignificant age changes (Table 2). The narrowest region was found at the $\mathrm{C} 4$ level 
Table 3. The Values of Torg Ratio Among The Subject By Age and Sex

\begin{tabular}{|c|c|c|c|c|c|c|c|c|c|c|c|}
\hline & \multirow[t]{2}{*}{ Decades } & \multicolumn{2}{|c|}{1} & \multicolumn{2}{|l|}{2} & \multicolumn{2}{|c|}{3} & \multicolumn{2}{|c|}{4} & \multicolumn{2}{|l|}{5} \\
\hline & & Mean & StD & Mean & StD & Mean & StD & Mean & StD & Mean & StD \\
\hline \multirow{2}{*}{$\mathrm{C} 2$} & Male & $1,36 \mathrm{a}$ & 0,16 & $1,29 \mathrm{ab}$ & 0,18 & $1,18 \mathrm{c}$ & 0,15 & $1,17 \mathrm{c}$ & 0,13 & $1,19 \mathrm{bc}$ & 0,14 \\
\hline & Female & $1,28 \mathrm{ab}$ & 0,20 & $1,28 \mathrm{ab}$ & 0,18 & $1,37 \mathrm{a}$ & 0,16 & $1,16 \mathrm{c}$ & 0,14 & $1,19 \mathrm{bc}$ & 0,18 \\
\hline \multirow{2}{*}{ C3 } & Male & $1,14 \mathrm{a}$ & 0,16 & $1,06 \mathrm{ab}$ & 0,14 & $0,99 \mathrm{~b}$ & 0,11 & $0,98 \mathrm{bc}$ & 0,17 & $0,90 \mathrm{c}$ & 0,11 \\
\hline & Female & $1,09 \mathrm{a}$ & 0,15 & $1,03 \mathrm{ab}$ & 0,12 & $1,05 \mathrm{ab}$ & 0,10 & $1,01 \mathrm{ab}$ & 0,14 & $1,00 \mathrm{~b}$ & 0,13 \\
\hline \multirow{2}{*}{$\mathrm{C} 4$} & Male & $1,08 \mathrm{a}$ & 0,17 & $0,99 \mathrm{ab}$ & 0,13 & $0,95 \mathrm{bc}$ & 0,20 & $0,98 \mathrm{~b}$ & 0,14 & $0,86 \mathrm{c}$ & 0,10 \\
\hline & Female & $1,07 \mathrm{a}$ & 0,17 & $1,01 \mathrm{a}$ & 0,12 & $1,01 \mathrm{a}$ & 0,12 & $1,01 \mathrm{a}$ & 0,14 & 1,03a \# & 0,20 \\
\hline \multirow{2}{*}{ C5 } & Male & $1,10 \mathrm{a}$ & 0,18 & $1,01 \mathrm{ab}$ & 0,12 & $0,97 \mathrm{~b}$ & 0,13 & $0,97 \mathrm{~b}$ & 0,16 & $0,86 \mathrm{c}$ & 0,12 \\
\hline & Female & $1,12 \mathrm{a}$ & 0,35 & $1,01 \mathrm{ab}$ & 0,15 & $1,03 \mathrm{ab}$ & 0,12 & $0,99 \mathrm{~b}$ & 0,13 & $0,99 \mathrm{~b}$ & 0,14 \\
\hline \multirow{2}{*}{ C6 } & Male & $1,06 \mathrm{a}$ & 0,72 & $1,00 \mathrm{~b}$ & 0,14 & $0,96 \mathrm{bc}$ & 0,11 & $0,94 \mathrm{bc}$ & 0,18 & $0,84 \mathrm{c}$ & 0,15 \\
\hline & Female & $1,04 \mathrm{a}$ & 0,13 & $1,00 \mathrm{a}$ & 0,12 & $1,02 \mathrm{a}$ & 0,12 & $0,94 \mathrm{a}$ & 0,15 & $0,91 \mathrm{a}$ & 0,13 \\
\hline \multirow{2}{*}{$\mathrm{C} 7$} & Male & $1,05 \mathrm{a}$ & 0,13 & $0,96 \mathrm{~b}$ & 0,13 & $0,92 \mathrm{bc}$ & 0,08 & $0,90 \mathrm{bc}$ & 0,12 & $0,85 \mathrm{c}$ & 0,08 \\
\hline & Female & $1,04 \mathrm{a}$ & 0,12 & $1,00 \mathrm{ab}$ & 0,15 & $0,96 \mathrm{bc}$ & 0,09 & $0,93 \mathrm{bc}$ & 0,12 & $0,91 \mathrm{c}$ & 0,13 \\
\hline
\end{tabular}

Std (standard deviation)

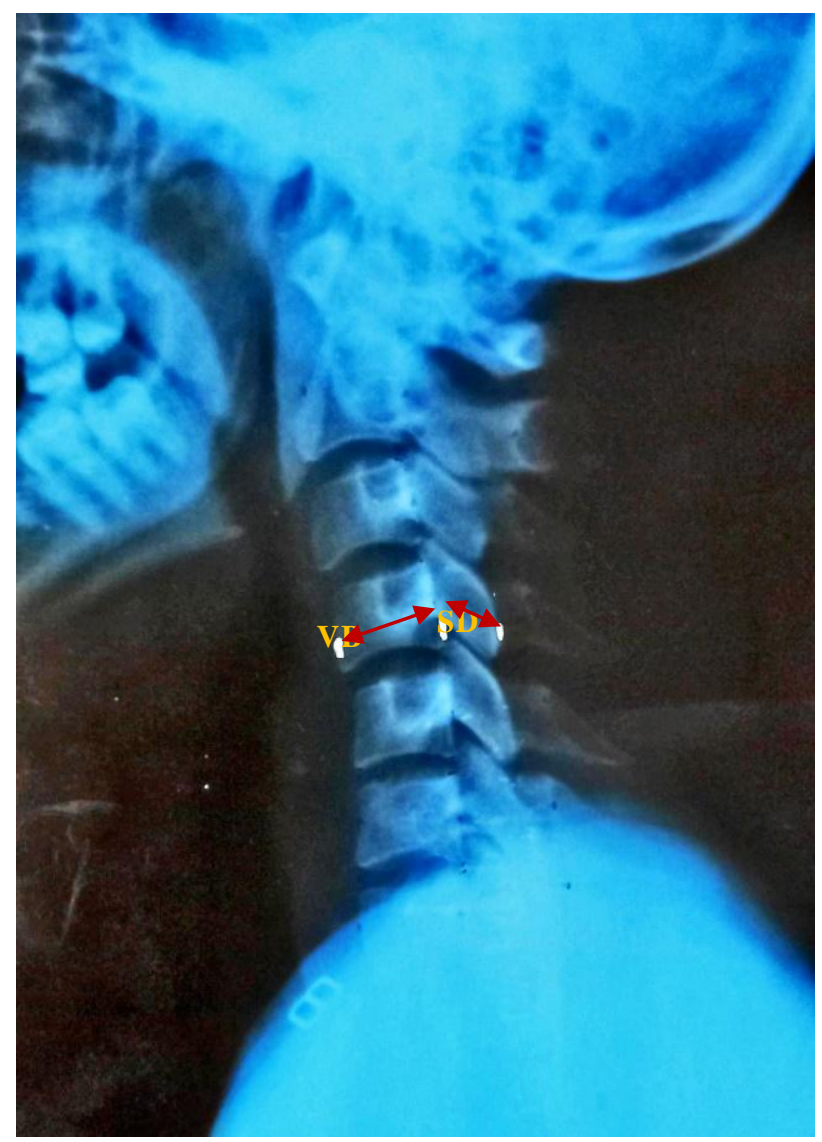

Fig. 1. Sagittal diameter (SD) and vertebral body (VB) were determined and marked

in most of the age groups in males. In female, however, the smallest diameter was not found to be consistent in any level and showed variations. VB changed with age significantly in both sex, and showed sex difference in every decade, in favour of male.

Torg ratio changes by sex and age groups
In both male and female, Torg ratio was generally found above 0.9 in all of the decades. Expect for C4 and C6 levels of all decades in females, Torg ratio changed with age significantly in all levels throughout the decades (Table 3, Figure 3). Gender difference was found to be insignificant at all level, except that female dominancy at $\mathrm{C} 4$ level of fifth decade was only observed (Table 3). Changes found from the present study are giving in detail at the following:

C2: During the decades, it continued with a highest value than the other levels in both sex. In male, C2 value showed a decreasing trend from the first decade to the third, and then a steady course to last decade. In female, it continued stably to the second decade, and then coursed increasingly to third decade. After a sharp decrease between third and fourth decades, C2 showed a slight increasing trend during the last decade.

C3: In male, it seemed as second high value. Excluding the horizontal course between the third and fourth decades, this value showed a decreasing trend from first decade to the last. In female, after a slightly decrease to the second decade, it continued generally to the end with a horizontal course.

C4: In male, while it showed a similar trend to C3 from the beginning to the end, this value coursed with a slight increase between the third and the fourth decades. In female, after a slight decrease by the second decade, it continued horizontally to the end.

C5: In male, it showed a parallel course to that of C3 during the decades. In female, after a decrease 

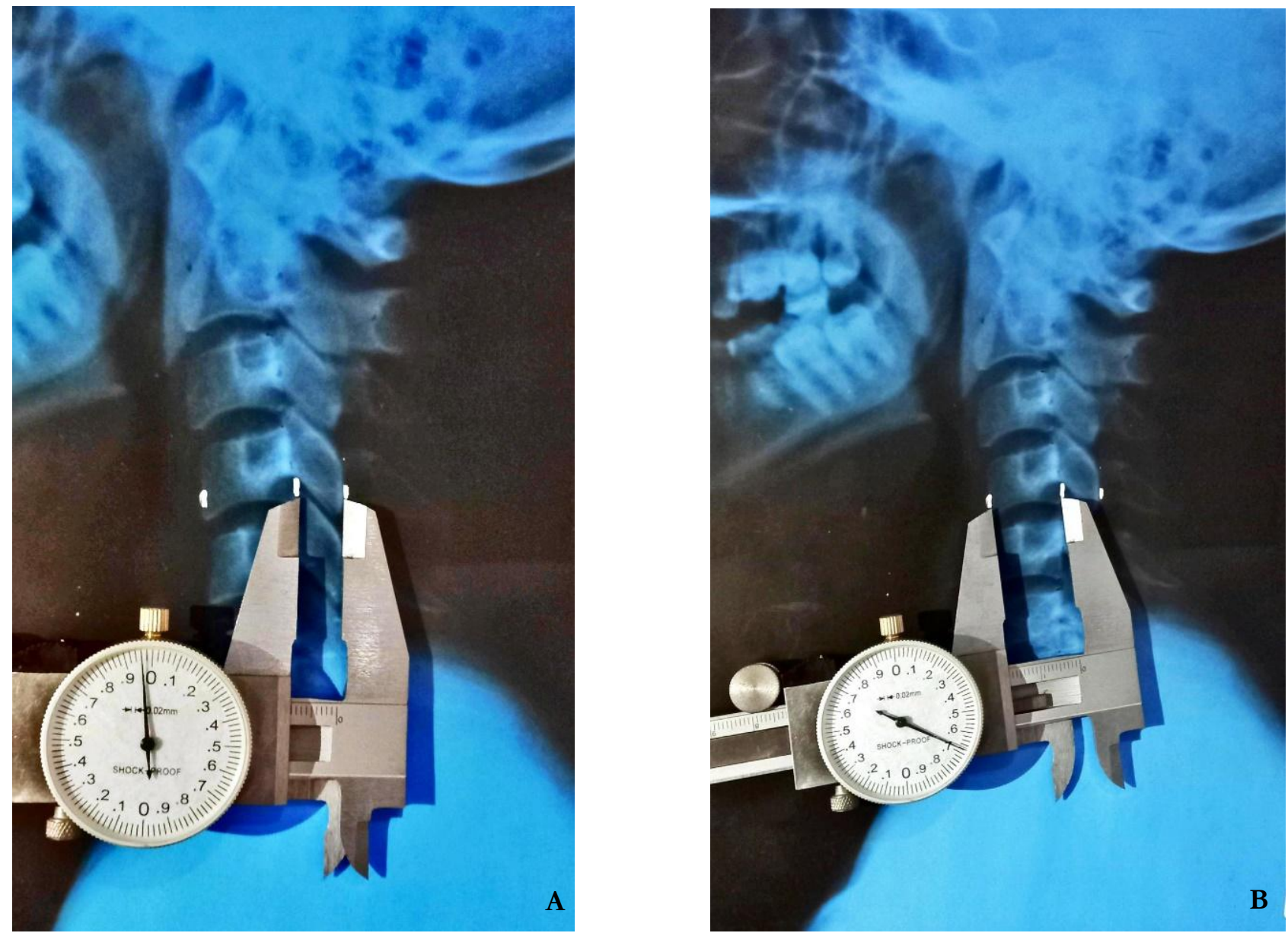

Fig. 2. The Marked Points (A: Spinal Canal (SD) and B: Vertebral Body (VB)) Were Measured

by the second decades, it continued under and parallel to $\mathrm{C} 3$ by the end.

C6 and C7: In male, with lower values than the others, these values showed a decreasing trend from the beginning to the end. In female, these values made a diagram similar to that of male.

Data Analysis: Descriptive statistics are presented as mean and standard deviation for the variables in Tables. Factorial Variance Analysis was used to determine differences means of decades and gender. Duncan (multiple comparison) test was then used. $p$ value of 0.05 and less was considered as statistically significant for all analyses and comparisons. Statistical analyses were performed using IBM SPSS Statistics for Windows, Version 21.0 software (IBM Corp., Armonk, NY, USA).

\section{Discussion}

Several morphologic studies have measured the cervical SD to evaluate cervical spinal disorders. It has been stated that the decreasing in sagittal diameter is one cause of the compressive myelopathy (12). Neurologic deficit is more likely in patient with smaller cervical SD than normal (14). If the sagittal canal diameter is less than 10 $\mathrm{mm}$, cord compression occurs (15). We observed SD over $16.74 \mathrm{~mm}$. It was concluded that Torg ratio is more reliable than the measurement of the $\mathrm{SD}$ in the diagnosis of cervical spinal stenosis or predicting the prognosis of cervical spinal cord injury (11). To date, the canal/body ratio were investigated in specific subject and age groups. This proportion was reported as 0.6 in the athletes with developmental stenosis and the persons with spinal disorders such that stenosis, instability, disc degeneration, or congenital anomalies (7). Torg ratio was found to be less than 0.80 in $69 \%$ of the total vertebral levels in normal subjects aged 20-25 (1) and between 0.83 and 0.89 in asymptomatic football player (16). We found the Torg ratio with mean of 1.15 and with a decreasing value from 1.36 to 1.04 cephalocaudally in all decades (Fig. 1, Table 3). Torg ratio less than 0.80 was reported to be extremely sensitive to screen for cervical spinal stenosis. Canal/body ratio values in normal subjects of specific groups studied seem to be variable, i.e. while some of them implicated the stenosis, the others denied it. The present study indicated that the occurrence of the cervical canal 


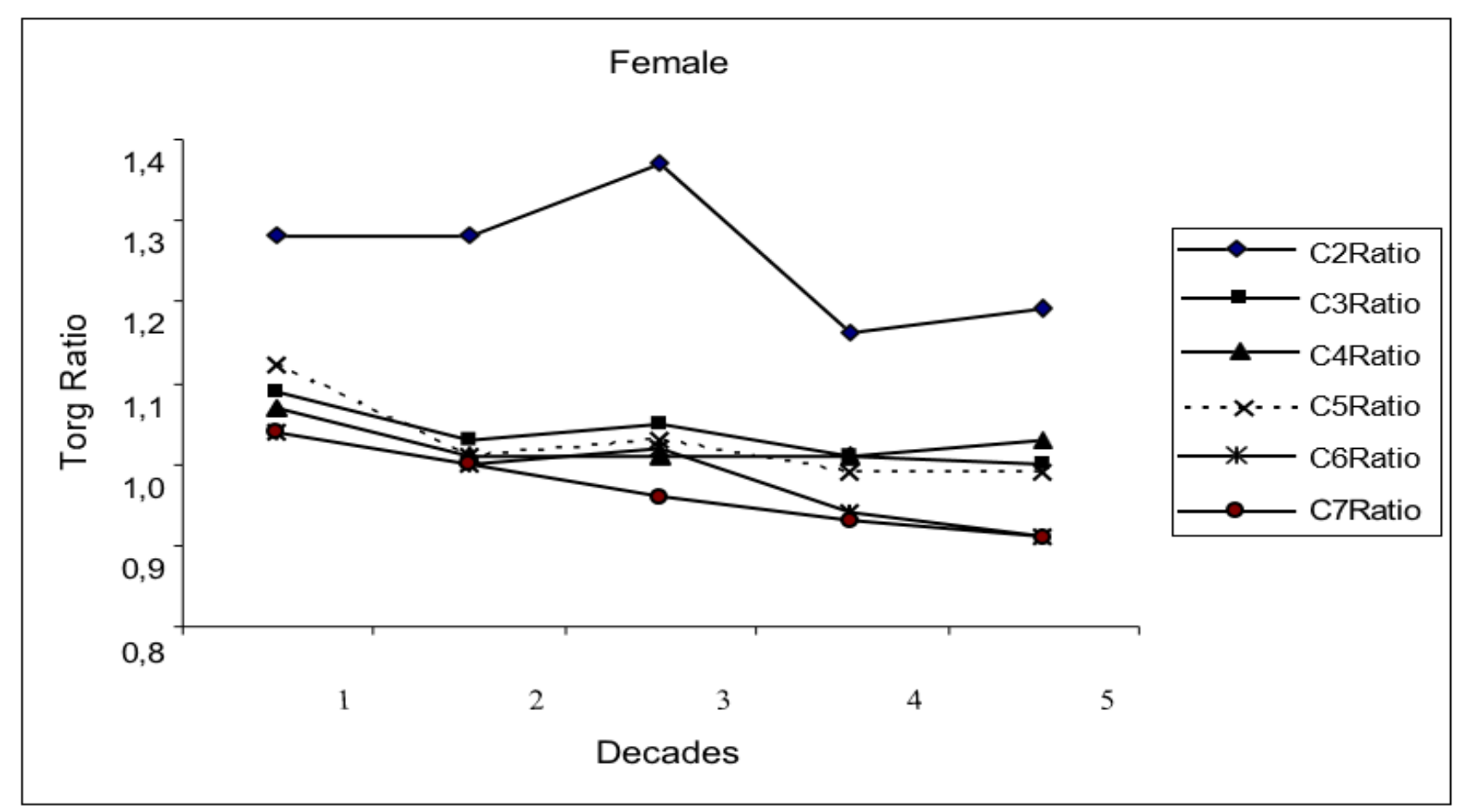

Fig. 3. Graphical Explanation of Age-Related Changes In Torg Ratio Values In Women. C: Cervical Vertebral Columns

stenosis in normal ageing subjects is unusual. The works reporting age change in SD and Torg ratio are limited. While, In Japanese, Tanaka (10) found the AP diameter of the spinal canal to become smaller with age, In Korean, SD indicated no change through the decades (11). In the present study, SD did not change with age (Table. 2). Therefore, age change of SD from the studies (our study included) did not agreed a consistent result. This situation might be resulted from that SD is not reliable parameter enough due to magnification errors. Indeed, the previous reports have addressed racial variation in SD, namely, the widest in Europeans and the smallest in Japanese (8). Ezra et al. (17) have conducted direct measurement at the cervical level of 277 African American and European American non-pathologic human skeletons between 20 and 60 years of age and haven't detected significant interactions with respect to age, ethnicity and gender in terms of Torg rates. In the present work, Torg ratio decreased with age significantly from 1.4 to 0.9 in both gender, sharply in male and slowly in female. Although this trend might suggest that the bony spinal canal gets narrower with age, it indicates no risk for cervical stenosis and or myelopathy. An unvarying course observed at C4 and C6 levels of all female decades is an interesting finding and needs to confirm or deny by the further works. In Chinese individuals aged 21 to 46 years, the canal/body ratio was found as mean of 0.87 , which indicates no risk for the stenosis (8). In adults, Robinson et al. (18) found a steady decrease in the canal/body ratio with age, which agree with that of the adults in the present study.

Female dominancy in Torg ratio have been declared in the specific groups $(8,19,20)$. On the other hand, the presence of a sex discrepancy in canal/body ratio was proposed in adulthood (18, 21). In other word, this ratio did not indicate a difference between genders until 15 years of age. It became, thereafter, consistently smaller in male than females by 39 years old, at every measured segment. We did not find any differences between the sexes for Torg ratio at all level of the decades, expect for fifth decade. At C4 level of the fifth decade, female over male asymmetry merely found, which was accepted as an incidental finding.

Contrary to the previous works, our study indicated no sex difference in Torg ratio at any level throughout the decades, which might be given the peculiarity of the population. The incidence of canal stenosis, defined by canal/body ratio, was found to be $19.4 \%$ for men and $4.4 \%$ for women in the population of healthy young japans adults who were mostly fresh graduates from colleges and high school. It is suggested that these subjects are more engaged in physical activity in these ages. In these studies, the data of the Torg ratio for elder decades is also missing. Variations in Torg ratio seem to exist among the populations, at least, in young decades. 


\section{References}

1. Tierney RT, Maldjian C, Mattacola CG, Straub SJ, Sitler MR. Cervical Spine Stenosis Measures in Normal Subjects. J Athl Train. 2002; 37: 190-193.

2. Torg JS, Corcoran TA, Thibault LE, et al. Cervical cord neurapraxia:classification, pathomechanics, morbidity, and management guidelines.Neurosurg. 1997; 87: 843-850.

3. Inoue $\mathrm{H}$, Ohmori $\mathrm{K}$, Takatsu $\mathrm{T}$, Teramoto $\mathrm{T}$, Ishida Y, Suzuki K. Morphological analysis of the cervical spinal canal, dural tube and spinal cord in normal individuals using CT myelography. Neuroradiology 1996; 38: 148-151.

4. asaki T, Kadoya S, Iizuka H. Roentgenological study of the sagittal diameter of the cervical spinal canal in normal adult Japanese. Neurol Med Chir (Tokyo) 1998; 38: 83-89.

5. Senol U, Cubuk M, Sindel $M$, et al. Anteroposterior diameter of the vertebral canal in cervical region: comparison of anatomical, computed tomographic, and plain film measurements. Clin Anat 2001; 14: 15-18.

6. Stanley JH, Schabel SI, Frey GD, Hungerford GD. Quantitative analysis of the cervical spinal canal by computed tomography. Neuroradiology 1986; 28: 139-143.

7. Torg JS, Pavlov H, Genuario SE, et al. Neurapraxia of the cervical spinal cord with transient quadriplegia. J Bone Joint Surg (Am) 1986; 68: 1354-1370.

8. Lim JK, Wong HK. Variation of the cervical spinal Torg ratio with gender and ethnicity. Spine. J 2004; 4: 396-401.

9. Torg JS, Naranja RJ Jr, Pavlov H, Galinat BJ, Warren R, Stine RA. The relationship of developmental narrowing of the cervical spinal canal to reversible and irreversible injury of the cervical spinal cord in football players. J Bone Joint Surg (Am) 1996; 78: 1308-1314.

10. Tanaka Y. Morphological changes of the cervical spinal canal and cord due to aging. J Jpn Orthop Assoc 1984; 58: 873-886.

11. Lee HM, Kim NH, Kim HJ, Chung IH. Midsagittal canal diameter and vertebral body/canal ratio of the cervical spine in Koreans. Yonsei Med J 1994; 35: 446-452.

12. Ishikawa M, Matsumoto M, Fujimura $Y$, Chiba K, Toyama Y. Changes of cervical spinal cord and cervical spinal canal with age in asymptomatic subjects. Spinal Cord 2003; 41: 159-163.

13. Eismont FJ, Clifford S, Goldberg M, Green B. Cervical sagittal spinal canal size in spine injury. Spine 1984; 9: 663-666.

14. Gore DR, Sepic SB, Gardner GM. Roentgenographic findings of the cervical spine in asymptomatic people. Spine 1986; 11: 521-524.

15. Herzog RJ, Wiens JJ, Dillingham MF, Sontag MJ. Normal cervical spine morphometry and cervical spinal stenosis in asymptomatic professional football players. Plain film radiography, multiplanar computed tomography, and magnetic resonance imaging. Spine 1991; 16: 178-186.

16. Ezra D, Slon V, Kedar E, et al. The Torg Ratio of C3-C7 in African Americans and European Americans: A Skeletal Study. Clinical Anatomy 2019; 32: 84-89.

17. Robinson MD, Northrup B, Sabo R. Cervical spinal canal plasticity in children as determined by the vertebral body ratio technique. Spine. 1990; 15: 1003-1005.

18. Kar M, Bhaumik D, Ishore K, Saha PK. MRI Study on Spinal Canal Morphometry: An Indian Study. Journal of clinical and Diagnostic Research 2017; 11: 8-11.

19. Pavlov H, Torg JS, Robie B, Jahre C. Cervical spinal stenosis: determination with vertebral body ratio method. Radiology 1987; 164: 771-775.

20. Hukuda S, Kojima Y. Sex discrepancy in the canal/body ratio of the cervical spine implicating the prevalence of cervical myelopathy in men. Spine 2002; 27: 250-253.

21. Rijal B, Pokharel RK, Paudel S, Shah LL. Torg's Ratio in Normal Adult Nepalese Population. Journal of Society of Surgeons of Nepal 2015; 18: 5-9.

\footnotetext{
East J Med Volume:26, Number:4, October-December/2021
} 